\title{
HEMODYNAMIC CHANGES AND AUTONOMIC NERVOUS SYSTEM AFTER ACUTE MYOCARDIAL INFARCTION IN RATS SUBMITTED TO LEFT CORONARY ARTERY LIGATION
}

Clin Biomed Res. 2018;38(2):132-140

1 Departamento de Fisiologia, Instituto de Ciências Básicas da Saúde, Universidade Federal do Rio Grande do Sul (UFRGS). Porto Alegre, RS, Brasil.

2 Instituto Porto Alegre. Porto Alegre, RS, Brasil.

3 Serviço de Endocrinologia, Hospital de Clínicas de Porto Alegre (HCPA), Universidade Federal do Rio Grande do Sul (UFRGS). Porto Alegre, RS, Brasil.

4 Laboratório de Fisiologia Cardiovascular, Universidade Federal de Ciências da Saúde de Porto Alegre (UFCSPA). Porto Alegre, RS, Brasil.

5 Unidade de Hipertensão, Instituto do Coração, Universidade de São Paulo (USP). São Paulo, SP, Brasil.

Corresponding author: Maria Cláudia Irigoyen hipirigoyen@incor.usp.br Unidade de Hipertensão, Instituto do Coração (InCor), Universidade de São Paulo (USP)

Av. Enéas de Carvalho Aguiar, 44. 05403-000, São Paulo, SP, Brasil.

\author{
Daniela Meirelles do Nascimento ${ }^{1,2}$, Beatriz D'Agord Schaan ${ }^{3}$, \\ Adriane Belló-Klein ${ }^{1}$, Pedro Dal Lago ${ }^{4}$, Maria Cláudia Irigoyen ${ }^{5}$
}

\section{ABSTRACT}

Introduction: Heart failure is a clinical syndrome characterized by sympathetic/ renin-angiotensin system activation, besides parasympathetic activity attenuation. In the initial phase of HF, following a myocardial infarction, there is impairment of the ventricular function and this can be influenced by the myocardium ischemia area in addition to alteration in the autonomic control of the heart. The aim of this study is to evaluate the hemodynamic responses and autonomic nervous system and its associations in infarcted rats by left coronary artery ligation.

Methods: Forty male rats were submitted to left coronary artery ligation: infarcted animals with fifteen days from cardiac surgery (I15), infarcted animals with thirty days from cardiac surgery (I30) and sham-operated groups (S15 and S30), with 10 animals in each group. Basal hemodynamic data and heart rate variability (spectral analysis) were evaluated.

Results: Compared to control groups, the infarcted rats demonstrated the following complications: a) cardiac hypertrophy (I30); b) pulmonary congestion (I30); c) mean arterial pressure (MAP), systolic arterial pressure (SAP) and diastolic arterial pressure (DAP) reduction; d) left ventricular systolic pressure (LVSP) reduction and left ventricular end-diastolic pressure (LVEDP) rise; e) contractile $(+d P / d t)$ and relaxation derivatives $(-\mathrm{dP} / \mathrm{dt})$ reduction; f) sympathetic cardiac activity increase, and parasympathetic cardiac activity reduction (I30).

Conclusion: Our study shows that the infarcted animals presented left ventricular dysfunction, which was influenced by the infarct size. In addition, impairment of autonomic control was present only in the animals belonging to the 130 group, probably due to the degree of cardiac decompensation and disease progression.

Keywords: Heart failure; myocardial infarction; heart rate variability

Heart failure is a major and growing public health problem in the United States ${ }^{1}$. Despite the progress made with medical and device-based therapies, the number of annual hospital admissions due to heart failure continues to increase, posing a substantial burden on healthcare resources ${ }^{2}$. Heart failure is characterized by neurohumoral adaptations such as sympathetic nervous system and renin-angiotensin system activation, increased plasma anti-diuretic hormone, and parasympathetic withdrawal, which are implicated in the progressiveness of the syndrome ${ }^{3}$.

Heart failure is a multifactorial systemic disease in which, after cardiac injury, structural, neurohumoral, cellular, and molecular mechanisms are activated and act as a network to maintain physiological functioning. These processes lead to excessive volume overload, increased sympathetic activity, circulation redistribution, and result in different parallel developing clinical signs and symptoms $\mathrm{s}^{4,5}$.

Coronary artery disease is an important cause of heart failure, accounting for two-thirds of patients with left ventricular systolic dysfunction. In most of 
these cases, it is a consequence of a myocardial infarction (MI), a situation that marks the exact moment of the myocardium damage ${ }^{6-8}$. Although there is no animal model that can mimic entirely the pattern of human heart failure, the most commonly used animal model to study this condition is the complete coronary occlusion by ligation ${ }^{9}$.

The interactions between the heart and the autonomic nervous system (ANS) have been known for several decades. The ANS has two primary components: the sympathetic and parasympathetic systems. The sympathetic nervous system (SNS) is the cardio-stimulatory pathway, which increases heart rate and force of contraction, while the parasympathetic nervous system (PNS) is the cardio-inhibitory pathway and acts through reducing the heart rate, blood pressure, and contractility ${ }^{10}$. The importance of slowing down heart failure progressiveness brought interest in the comprehension of pathophysiologic mechanisms responsible for the imbalance between sympathetic and parasympathetic systems in this syndrome ${ }^{11}$. In a heart that becomes insufficient, as angiotensin II and norepinephrine increase, the inhibitory input from the baroreceptor afferent vessels decreases while the excitatory input increases, resulting in a sympathetic and parasympathetic tonus imbalance ${ }^{3}$. Data from animal and human studies show that the parasympathetic activity is attenuated in heart failure. Defective cardiac parasympathetic control in patients with heart disease and augmentation of the sympathetic activity appears to be related to the parasympathetic withdrawal. In addition, the cardiac parasympathetic tonus has an inhibitory effect upon sympathetic activity ${ }^{12}$.

Experimental evidence for an association between pathological conditions, such as acute $\mathrm{MI}$ and heart failure, and signs of increased sympathetic or reduced vagal activity has aroused interest in the development of quantitative markers of autonomic activity ${ }^{13}$. The heart rate variability (HRV) is one of the techniques used in its evaluation, which describes the oscillations in the interval between consecutive heart beats (RR interval), as well as the oscillations between consecutive instantaneous heart rates. Higher HRV is a signal of good adaptation and characterizes a healthy person with efficient autonomic mechanisms, while lower HRV is frequently an indicator of abnormal and insufficient adaptation of the ANS, provoking a poor physiological function ${ }^{14}$.

We hypothesized that acute MI, early and late, leads to changes in the autonomic nervous system. To investigate this hypothesis, this study evaluates the hemodynamic responses and autonomic imbalance through the evaluation of HRV in infarcted rats after left coronary artery ligation.

\section{METHODS}

\section{Animals and Experimental Procedures}

Experiments were performed on male Wistar rats (250-300g) from the Animal House of the Universidade Federal do Rio Grande do Sul, Porto Alegre, Brazil. The animals received rat chow and water ad libitum and were maintained on a 12:12-h light-dark cycle. They were acclimatized for one week, then fasted overnight and submitted to the surgical procedures as described below.

The experimental protocol was approved by the Institutional Animal Care and Use Committee of the Instituto de Ciências Básicas da Saúde of the Universidade Federal do Rio Grande do Sul, and this investigation was conducted in accordance with the Guide for the Care and Use of Laboratory Animals: National Research Council ${ }^{15}$.

The animals were randomly assigned to sham (with 15 or 30 days from the sham surgical procedure; S15 and S30) or infarct group (with 15 or 30 days from myocardial infarction surgery; 115 and 130), each with 10 animals.

In order to detect a difference in the low frequency/high frequency ratio (LF/HF), that indicates the sympathovagal balance, between groups of $11 \mathrm{NU}$ (normalized units), considering a standard deviation of 0.06 , power of $90 \%$ and level of significance of $5 \%, 10$ animals were included per group ( $n=40$ animals). The sample size was based on the findings of Mostarda et al. ${ }^{16}$.

\section{Coronary Artery Ligation Surgery}

Myocardial infarction was induced in rats anesthetized by intraperitoneal (i.p.) injection of $80-\mathrm{mg} / \mathrm{kg}$ ketamine (Parke-Davis, Ann Arbor, MI) and 12-mg/kg xylazine (Bayer, Newhaven, CT). After intubation, animals were ventilated with positive-pressure with room air $(2.5 \mathrm{~mL} / \mathrm{kg})$, at the respiratory rate of $65 \mathrm{rpm}$ with a pressure-cycled rodent ventilator (Harvard Apparatus, Model 683, Holliston, MA). For induction of myocardial infarction, a 2-cm left lateral thoracotomy was performed in the third intercostal space and the left anterior descending coronary artery was occluded with a single nylon (6.0) suture at approximately $1 \mathrm{~mm}$ from its origin below the tip of the left atrium, as previously described 6 . The chest was closed with silk suture. The animals were maintained in the ventilator until recovery. All rats received one dose of antibiotic (25 mg/kg cephalotin - Keflin Neutro $\left.{ }^{\circledR}\right)$.

\section{Arterial and Venous Catheterization}

Fourteen and 29 days after cardiac surgery, the animals were anesthetized with ketamine $(80 \mathrm{mg} / \mathrm{kg}$, i.p.) and xylazine (12 mg/kg, i.p.). Two Tygon catheters 
(P10) filled with saline were introduced into the right femoral artery and vein for direct measurements of blood pressure and drug administration, respectively. The catheters were exteriorized through the back of the neck.

\section{Hemodynamic Function Assessment Arterial Pressure (AP) and left ventricular pressure records}

One day after the vessel catheterization (I15: 15th and I30: 30 th day) the rats, in a conscious state and moving freely, had their AP recorded for 15 minutes through a connection between femoral artery catheter and a pressure transducer (Strain-Gauge - Narco Biosystem Miniature Pulse Transducer RP-155, Houston, Texas, USA). The transducer was connected to a sign amplifier (Pressure Amplifier HP 8805C) and a 16-channel analog-to-digital interface (CODAS - Data Acquisition System, PC 486), and continuously sampled $(2 \mathrm{kHz})$ in an IBM/PC.

The rats were anesthetized with pentobarbital sodium ( $40 \mathrm{mg} / \mathrm{kg}$, i.v.) to introduce a polyethylene catheter (P50) into the left ventricle through the right carotid artery. The correct position of the catheter was determined by the observation of the left ventricular pressure wave depicted on the computer screen. After 5 minutes, the ventricular pressure was registered for 5 minutes using the same system/software described above for AP evaluation. The higher left systolic ventricular pressure (LSVP) was determined by detection of maximum and minimum values of the curve pressure, beat by beat, providing systolic ventricular pressure. The left ventricular end-diastolic pressure (LVEDP) was determined by manual detection of the inflection point of the left ventricular diastolic pressure curve. The contractile $(+\mathrm{dP} / \mathrm{dt})$ and relaxation $(-\mathrm{dP} / \mathrm{dt})$ derivatives were obtained from left ventricular pressure curve and its maximum and minimum values, beat-by-beat.

\section{Heart Rate (HR) Variability}

Beat-by-beat values of systolic, diastolic and mean AP were identified from the AP record, from which pulse interval (PI) and HR were calculated as the interval between successive systolic pressure values by using the computer software (CODAS Dataq, Inc). The computer program automatically calculated the power spectral density (PSD) by using a maximal entropy method. Derived PSD of R-R interval variability contained two major components in power: a low frequency (LF, 0.05 to $0.15 \mathrm{~Hz}$ ) and a high frequency $(\mathrm{HF}, 0.15$ to $1.0 \mathrm{~Hz})$ band $^{17}$. The measurement of LF and HF components is usually made in absolute values of power (milliseconds squared). However, LF and HF may also be measured in normalized units, which emphasizes the controlled and balanced behavior of the two branches of the autonomic nervous system ${ }^{13}$. The high frequency band was used as an index of parasympathetic modulation and the low frequency band was used as an index of sympathetic activity. The ratio of low to high frequency (LF/HF) bands was used as an index of sympathetic and parasympathetic balance ${ }^{13,17}$.

\section{Morphometric Evaluation}

Immediately after the procedures described above, the rats were killed by a pentobarbital overdose. The heart was removed, the atria were separated from the ventricles. The right ventricle, left ventricle, and interventricular septum were dissected, separated, and weighed. The total weight of the heart and each part were measured. The cardiac, right and left hypertrophy index $(\mathrm{mg} / \mathrm{g})$ were respectively calculated by the ratio of heart weight and body weight, right ventricle weight and body weight, and left weight and body weight ${ }^{6}$.

Pulmonary and hepatic congestion were evaluated by dissecting and weighing these organs. The ratio of wet weight and body weight were used to determine the congestion ${ }^{18}$.

The infarcted size was obtained by manual planimetry, isolating the left ventricle scar. The infarcted and non-infarcted areas of the left ventricle, in addition to the right ventricle area, were placed on a paper and drawn. Afterward, the paper was cut and weighed. The infarcted size was calculated by the ratio of infarcted area mass and the sum of the left and right ventricle mass ${ }^{19}$.

\section{Statistical Analysis}

Data are reported as mean \pm SD. Repeated measures two-way ANOVA was performed, with Student-Newmann-Keuls as post-test. The Pearson's correlation coefficient was used for the correlations between variables. Differences were considered to be significant at $p<0.05$. The statistical analysis used the GraphPad Instat software, version 3.0 for Windows 95 (GraphPad Software, San Diego, California, USA).

\section{RESULTS}

The infarct size was determined as a percentage of the left ventricle total area, as an indication of ventricular dysfunction. The infarct size was $35.1 \pm 9.1 \%$ in the 115 group and $31.7 \pm 11.5 \%$ in the 130 group, which were similar $(p=0.474)$. 
Table 1: Biometric, Morphometric and Hemodynamic Indexes of Control, I15 and I30 Animal Groups.

\begin{tabular}{|c|c|c|c|c|}
\hline Sample Size $(n=40)$ & S15 $(n=10)$ & $S 30(n=10)$ & $115(n=10)$ & $130(n=10)$ \\
\hline Initial Body Weight (g) & $243.7 \pm 27$ & $239.3 \pm 24.7$ & $251.6 \pm 31.5$ & $232.2 \pm 18.5$ \\
\hline Final Body Weight (g) & $276.4 \pm 35.2$ & $281.4 \pm 40.2$ & $274 \pm 37.7$ & $282.2 \pm 52.6$ \\
\hline Infarct Size (\%) & & & $35.1 \pm 9.1$ & $31.7 \pm 11.5$ \\
\hline Heart Weight/Body Weight (mg/g) & $2.58 \pm 0.2$ & $2.54 \pm 0.1$ & $2.65 \pm 0.2$ & $3 \pm 0.2^{\S}$ \\
\hline Left Ventricle Weight/ Body Weight $(\mathrm{mg} / \mathrm{g})$ & $2.06 \pm 0.1$ & $2.03 \pm 0.1$ & $2.17 \pm 0.2^{*}$ & $2.25 \pm 0.2^{\ddagger}$ \\
\hline Right Ventricle Weight/ Body Weight (mg/g) & $0.52 \pm 0.07$ & $0.5 \pm 0.09$ & $0.57 \pm 0.1$ & $0.68 \pm 0.2^{\ddagger *}$ \\
\hline Wet Lung Weight/Body Weight (mg/g) & $5.7 \pm 0.6$ & $5.2 \pm 0.7$ & $6.3 \pm 1.4$ & $7.5 \pm 2.7^{*}$ \\
\hline MAP $(\mathrm{mmHg})$ & $102.3 \pm 5$ & $105.9 \pm 5.6$ & $91 \pm 10^{\S}$ & $91.7 \pm 7 \S$ \\
\hline $\mathrm{SAP}(\mathrm{mmHg})$ & $122.1 \pm 5.9$ & $125.9 \pm 6.5$ & $107.2 \pm 13^{\S}$ & $110.7 \pm 10^{\S}$ \\
\hline $\mathrm{DAP}(\mathrm{mmHg})$ & $84.0 \pm 5.8$ & $87.1 \pm 6$ & $79.6 \pm 5^{\S}$ & $79.9 \pm 5 \S$ \\
\hline HR (bpm) & $333.8 \pm 24.1$ & $340.5 \pm 23.1$ & $342.6 \pm 24$ & $347.7 \pm 39$ \\
\hline LVSP (mmHg) & $161.4 \pm 3.9$ & $162.7 \pm 4.2$ & $133.0 \pm 3^{\ddagger}$ & $150.6 \pm 4^{*}$ \\
\hline LVEDP (mmHg) & $1.3 \pm 2.5$ & $0.33 \pm 2.4$ & $7.87 \pm 3^{*}$ & $7.71 \pm 2^{\ddagger}$ \\
\hline$-\mathrm{dP} / \mathrm{dt}(\mathrm{mm} \mathrm{Hg} / \mathrm{s})$ & $-6857.12 \pm 398.7$ & $-7011.38 \pm 398.93$ & $-4854.17 \pm 258.3^{\S}$ & $-5488.55 \pm 259.8 \S$ \\
\hline$+\mathrm{dP} / \mathrm{dt}(\mathrm{mmHg} / \mathrm{s})$ & $8101.18 \pm 300.8$ & $8029.29 \pm 300.3$ & $5811.65 \pm 257.7^{\S}$ & $6744.72 \pm 298.3^{\S}$ \\
\hline
\end{tabular}

Data are presented as mean \pm SD. MAP: mean arterial pressure; SAP: systolic arterial pressure; DAP: diastolic arterial pressure; HR: heart rate; LSVP: left systolic ventricular pressure; LVEDP: left ventricular end-diastolic pressure; $-\mathrm{dP} / \mathrm{dt}$ : relaxation derivative; +dP/dt: contractility derivative; ${ }^{\S} p<0.001$ vs. $S ;{ }^{\ddagger} p<0.01$ vs. $S ;{ }^{*} p<0.05$ vs. S; ${ }^{*} p<0.05$ between infarcted groups (two-way ANOVA with Student-Newmann-Keuls as post-test).

All groups had similar body weight at the beginning of the study $(\sim 240 \mathrm{~g})(\mathrm{p}=0.109)$. Baseline cardiovascular, biometric, and morphometric data are presented in Table 1. At the end of 15 and 30 days from the surgical procedures, body weight was similar between all groups, infarcted and sham animals $(p=0.885)$. The heart weight/body weight index demonstrates that the 30-day infarcted animals had cardiac hypertrophy $(2.5 \pm 0.1,2.65 \pm 0.2$ and $3.0 \pm 0.2 \mathrm{mg} / \mathrm{g}$ in $\mathrm{S}$, $I 15$ and $I 30$ groups, respectively, $p<0.001$ ) and the wet lung /body weight ratio showed they had pulmonary congestion $(5.6 \pm 1,6.3 \pm 1.4$ and $7.5 \pm 2.7 \mathrm{mg} / \mathrm{g}$ in $\mathrm{S}, \mathrm{I} 15$ and $\mathrm{I} 30$ groups, respectively, $\mathrm{p}<0.05$ ).

Table 1 also shows that the heart rate was similar between groups, as well as the systolic, diastolic and mean arterial pressure at baseline, which were reduced in the infarcted $v s$. control rats $(p<0.001)$. The LVSP was diminished 15 and 30 days after coronary artery ligation $(p<0.01$ and $p<0.05$ vs. $S$, respectively). The LVEDP was increased in both periods of evaluation (I15 and I30 groups vs. S with $p<0.05$ and $p<0.01$, respectively). Ventricular contractile and relaxation derivatives, expressed by the $+\mathrm{dP} / \mathrm{dt}$ and $-\mathrm{dP} / \mathrm{dt}$, were both reduced in $\mathrm{I} 15$ and $\mathrm{I} 30 \mathrm{vs.} \mathrm{S}(\mathrm{p}<0.001)$.

There were positive correlations between cardiac hypertrophy and the infarct size $(r=0.4, p=0.0048)$ (Figure 1) and $+d P / d t$ and LVSP $(r=0.7, p<0.0001)$ (Figure 2). Otherwise, there were negative correlations between $-\mathrm{dP} / \mathrm{dt}$ and LVEDP ( $\mathrm{r}=-0.3, \mathrm{p}=0.0009)$ (Figure 3),

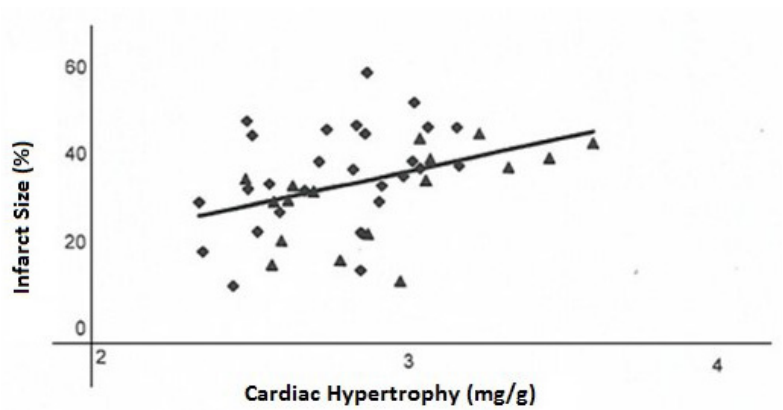

Figure 1: Correlation between cardiac hypertrophy and the infarct size in I15 ( $\diamond$ ) and I 30 ( $\Delta$ ) groups. $r=0.4, p=0.0048$. (Pearson's Correlation).

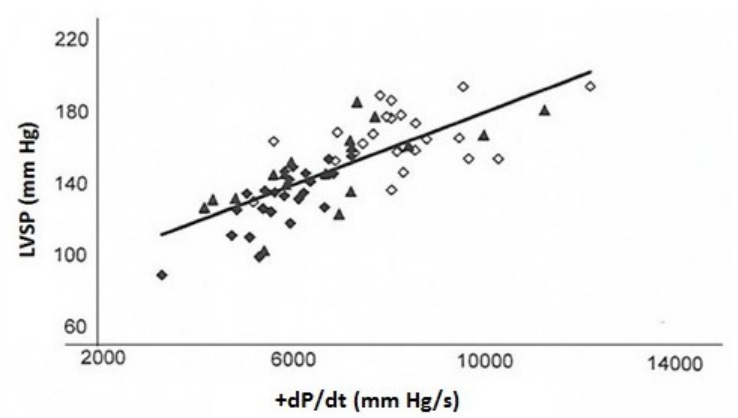

Figure 2: Correlation between LVSP (Left Ventricle Systolic Pressure) and $+d P / d t$ (Left Ventricle Contractile Derivate) in $S(\diamond), I 15(\diamond)$ and I30 ( $\Delta)$ groups. $r=0.7, p<0.0001$ (Pearson's Correlation). 
infarct size and MAP ( $r=-0.6, p=0.0222)$ (Figure 4), infarct size and SAP $(r=-0.6, p=0.01)$ (Figure 5), infarct size and LVSP $(r=-0.3, p<0.0001)$ (Figure 6$)$, infarct size and $-\mathrm{dP} / \mathrm{dt}(\mathrm{r}=-0.6, \mathrm{p}<0.0001)$ (Figure 7$)$, and infarct size and $+d P / d t(r=-0.5, p<0.0001)$ (Figure 8).

The data above confirm the effectiveness of this animal model of myocardial ischemia and the subsequent morphological and hemodynamic alterations following myocardial infarction.

The biometric and morphometric variables between the S15 and S30 groups did not show statistical differences and, therefore, the data of the spectral analysis of these animals were placed together in a single sham group. Figure 9 shows the results of the analysis of the heart rate variability. The 130 group had a significant increase in the LF(I30: $68 \pm 3$ vs. S: $45 \pm 4.8$ and $115: 53.6 \pm 9.8 \mathrm{NU}, p<0.01)$ and a reduction in the HF (I30: $32 \pm 3$ vs. S: $55 \pm 4.8$ and I15: $46.3 \pm 9.8 \mathrm{NU}, p<0.05)$ components (Panel A and B). The LF/HF ratio was higher in the 130 group, compared to the $S$ and $I 15$ groups (I30: $2.2 \pm 0.3$ vs. S: $0.8 \pm 0.2$ and I15: 1.2 $\pm 0.4 \mathrm{NU}, \mathrm{p}<0.01$ ) (Panel C).

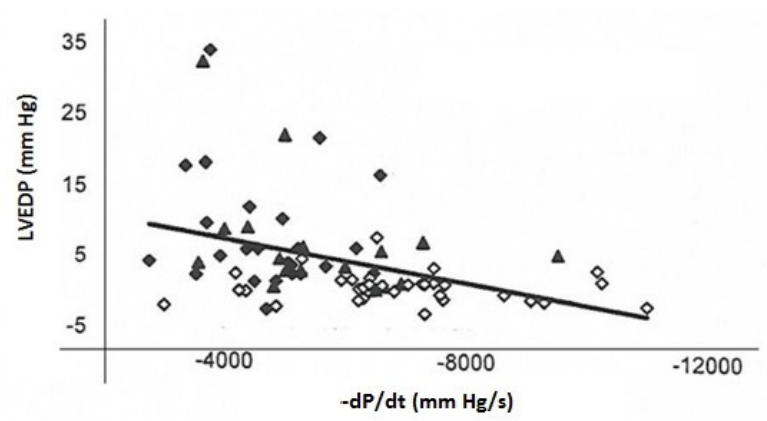

Figure 3: Correlation between -dP/dt (Left Ventricle Relaxation Derivate) and LVEDP (Left Ventricle End-Diastolic Pressure) in $S(\diamond), I 15(\diamond)$ and $\mathrm{I} 30(\boldsymbol{\Delta})$ groups. $r=-0.3, p=0.0009$ (Pearson's Correlation).

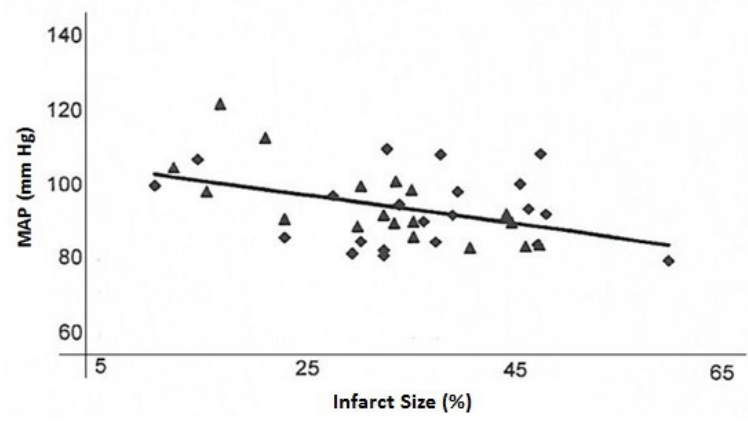

Figure 4: Correlation between infarct size and MAP (Mean Arterial Pressure) in I15 $(\downarrow)$ and I30 ( $\Delta$ ) groups. $r=-0.6$, $\mathrm{p}=0.0222$ (Pearson's Correlation).

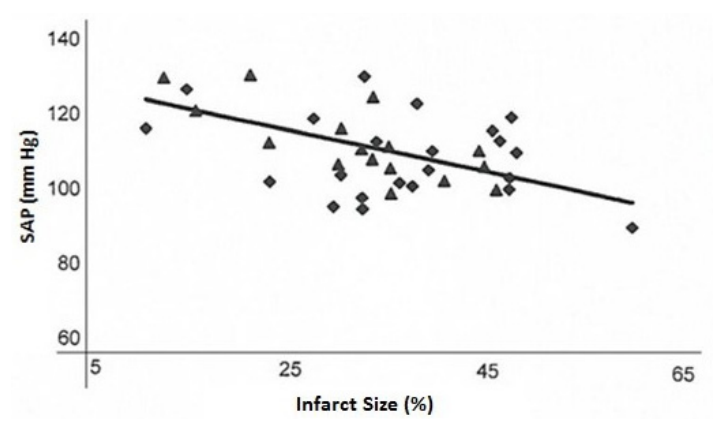

Figure 5: Correlation between infarct size and SAP (Systolic Arterial Pressure) in I15 ( $\diamond$ ) and I30 ( $\Delta$ ) groups. $r=-0.6$, $p=0.01$ (Pearson's Correlation).

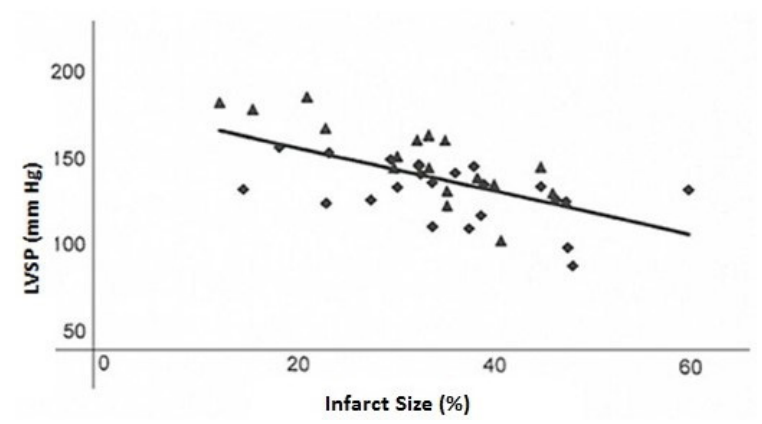

Figure 6: Correlation between infarct size and LVSP (Left Ventricle Systolic Pressure) in I15 ( $\bullet$ ) and I30 ( $\mathbf{\Delta}$ ) groups. $r=-0.3, p<0.0001$ (Pearson's Correlation).

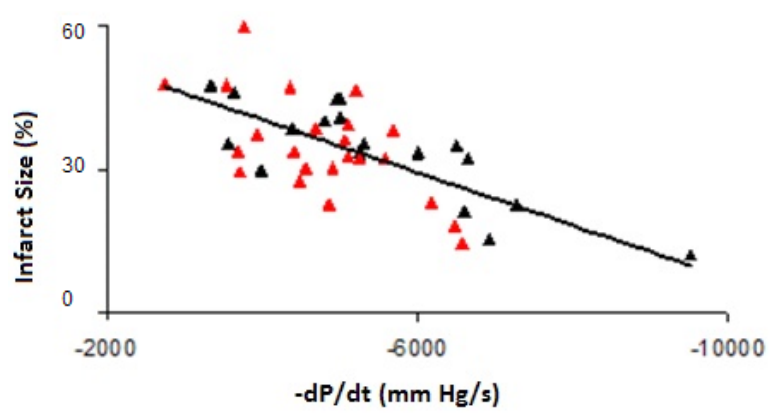

Figure 7: Correlation between infarct size and -dP/dt (Left Ventricle Relaxation Derivate) in I15 ( $\mathbf{\Delta}$ ) and $\mathrm{I} 30$ ( $\mathbf{\Delta}$ ) groups. $r=-0.6, p<0.0001$ (Pearson's Correlation).

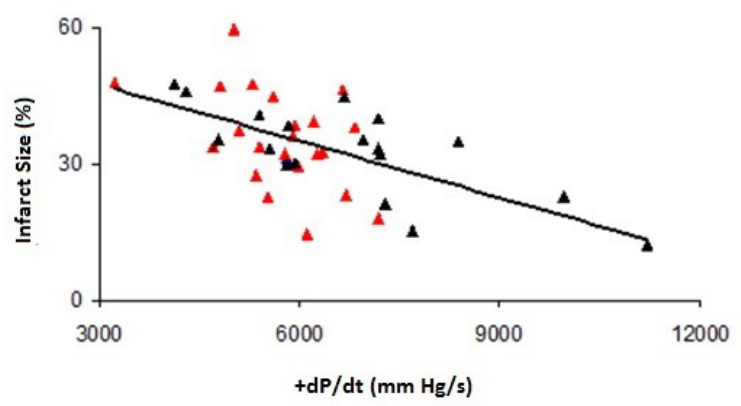

Figure 8: Correlation between infarct size and $+\mathrm{dP} / \mathrm{dt}$ (Left Ventricle Contractile Derivate) in I15 ( $\mathbf{\Delta}$ ) and I30 ( $\mathbf{\Delta}$ ) groups. $r=-0.5, p<0.0001$ ) (Pearson's Correlation). 

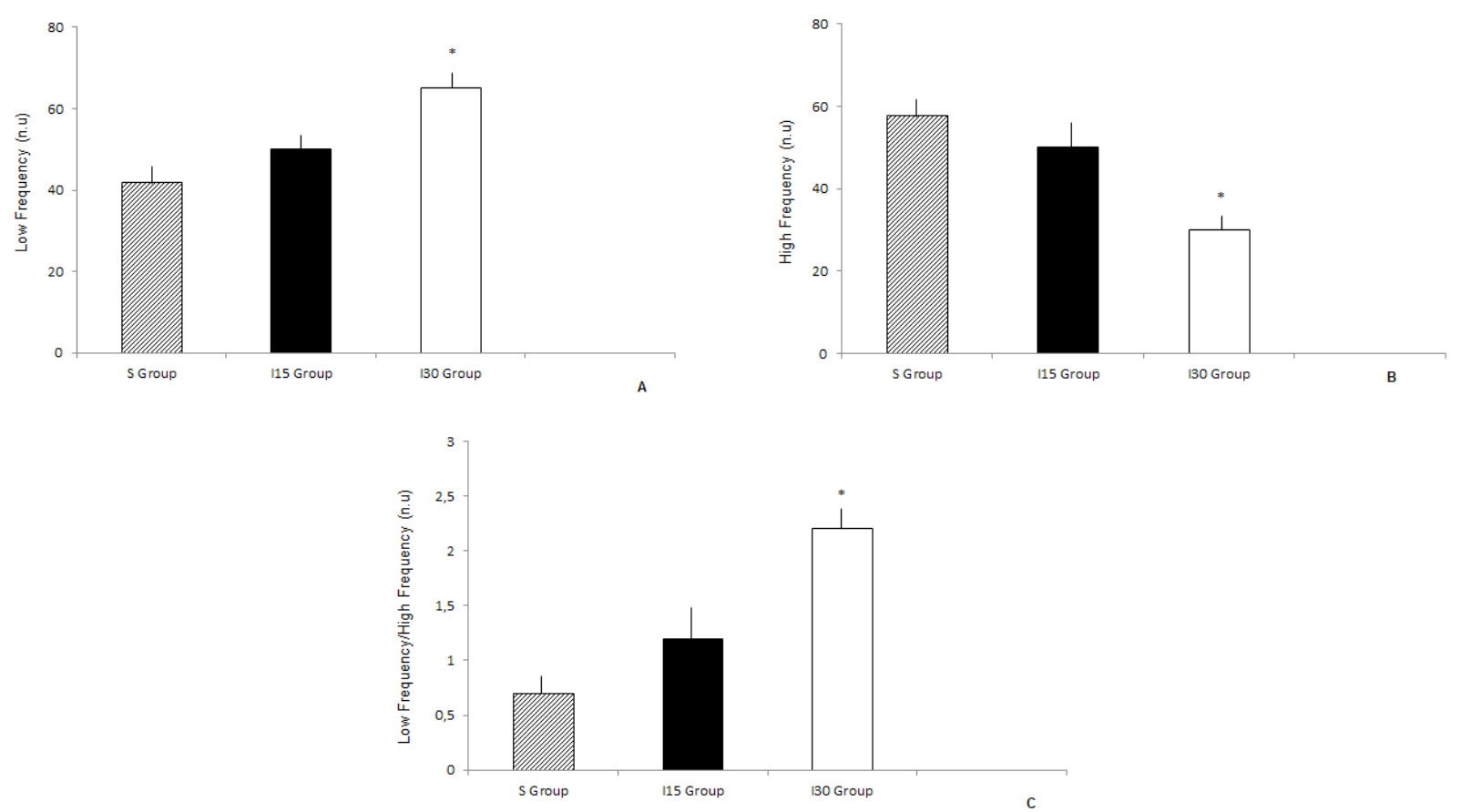

Figure 9: Heart rate variability: low frequency $(A)$ and high frequency $(B)$ components; low frequency/high frequency ratio (C). Data are presented as frequency component, as mean \pm SD. * $p<0.05$ from I30 vs. I15 and sham groups (two-way ANOVA, with Student-Newmann-Keuls as post-test).

\section{DISCUSSION}

This study shows depressed HRV after MI, which may reflect a decrease in vagal activity directed to the heart, leading to the prevalence of sympathetic mechanisms.

\section{Myocardial Infarction/Heart Failure Model}

The left coronary artery ligation is the most used experimental model for the induction of heart failure. This model produces marked left ventricular dysfunction that is directly related to the size of the infarcted area.

One of the pioneer studies of Pfeffer et al. ${ }^{6}$ demonstrated that only rats with infarcts with more than $47 \%$ of the left ventricle were associated with overt depression of left ventricular performance. However, in the present study, a moderate infarct size (31-46\%) was able to lead an elevated LVEDP and reduced in the MAP, $-\mathrm{dP} / \mathrm{dt}$ and $+\mathrm{dP} / \mathrm{dt}$, which confirms the effectiveness of myocardial infarction in leading to hemodynamic changes.

In all groups submitted to coronary artery ligation, the LVEDP, one of the most sensitive criteria of decreased left ventricular function ${ }^{6,18}$ was much higher compared to the S group, as shown earlier ${ }^{20}$. In addition, the heart weight/body weight and the lung weight/body weight indexes were higher in the I30 group, another characteristic that confirms moderate to severe impaired left ventricular systolic function.
When left ventricular filling pressure is elevated, right ventricular systolic pressure increases to maintain the pressure gradient across the pulmonary bed. Hence, the elevation of LVEDP produced by extensive infarction appears to result in the right ventricular hypertrophy ${ }^{21}$, as demonstrated in 130 animals. In fact, it could explain the presence of pulmonary congestion only in this group of animals, while in the initial phase after MI (I15 group), the heart was still able to maintain its function.

Also, the groups of infarcted animals showed lower $-\mathrm{dP} / \mathrm{dt}$ and $+\mathrm{dP} / \mathrm{dt}$ compared to the $\mathrm{S}$ group. A positive correlation was observed between the infarct size and cardiac hypertrophy, in line with previous observations that the large and transmural myocardial infarctions lead to important changes in the architecture of infarcted and non-infarcted zones (ventricular remodeling) ${ }^{6}$.

There was an inverse and significant correlation between the infarct size and the $-\mathrm{dP} / \mathrm{dt}$ and $+\mathrm{dP} / \mathrm{dt}$, demonstrating that the larger infarction hearts have a lower ventricular capacity of relaxation and contractility. A positive and significant correlation between $+\mathrm{dP} / \mathrm{dt}$ and LVSP was demonstrated; however, there was an inverse and significant correlation between cardiac hypertrophy and LVSP. Pathological hypertrophy is an adaptive response to hemodynamic overload, as it occurs after myocardial infarction in humans, but this response can result in left ventricular function deterioration, with impairment of ventricular relaxation 
(diastolic dysfunction) and contractility (systolic dysfunction ${ }^{22}$.

The LVSP, SAP, DAP and MAP were reduced in both infarcted groups, according to other studies and to our own previous data ${ }^{22,23}$. Acute Ml causes a reduction in the pumping capacity of the heart, which reduces cardiac output and blood pressure. These changes are directly related to the area of the left ventricle affected by the ischemic damage ${ }^{6,24}$, corroborating our findings.

The methodological limitation of this study - not having performed a more accurate assessment of myocardial infarct size, such as an echocardiographic evaluation - was overcome by the characteristic hemodynamic and morphometric changes described above, which clearly show left ventricular dysfunction in infarcted animals. Another limitation of this study is the mortality rate associated with this experimental model of myocardial infarction. These data were not evaluated in the study, since our group has used this procedure with a mortality of $40-50 \%$, which is in accordance with the literature ${ }^{6,18}$.

In summary, these observations clearly demonstrate the induction of early heart failure, between 15 and 30 days after myocardial infarction.

\section{Autonomic Dysfunction in the Myocardial Infarction/Heart Failure Model}

The spectral analysis of HRV is a method that can provide data on sympathetic and parasympathetic balance. While the sympathetic activity increases the frequency of cardiac beats, the parasympathetic activity is responsible for reducing the heart rate ${ }^{13}$.

A reduced HRV has been observed consistently in patients with cardiac disease since this condition is characterized by a sympathetic hyperactivity ${ }^{25}$.

Evidence has been provided that both the baroreflex control of HR and the HRV may be impaired after myocardial infarction, identifying subgroups of patients with a high susceptibility to malignant ventricular arrhythmias $^{26}$.

Previously, we show that the baroreflex control of $\mathrm{HR}$ is normal in anesthetized rats 30 days after a myocardial infarction and that these rats had higher spontaneous baroreceptor sensitivity of HR when submitted to exercise training compared to untrained rats $^{27,28}$. Also, the sympathetic tone was higher during the tachycardic phase after myocardial infarction. In a time-course evaluation, it was shown that HR normalization paralleled the progressive reduction of sympathetic tone, so the changes in HR after coronary artery ligation seemed to reflect the degree of sympathetic efferent activity during infarct healing ${ }^{17}$. In fact, our study did not evaluate the baroreflex control of HR.

In the present study, the spectral profile shows that in the 30-day, but not in the 15-day infarcted animals, there was an increase in the sympathetic activity (LF and LF/HF) but a reduction in the parasympathetic activity (HF).

The impairment of sympathovagal balance after MI seems to be transient. A gradual recovery of the normal autonomic activity in the heart after MI has been demonstrated. Aires et al. ${ }^{29}$ evaluated the time course of changes in autonomic balance. The HF component obtained from HRV was significantly reduced in the acute phase after infarction. Unlike our data, the parasympathetic activity was progressively recovered in the groups of animals studied 7 and 28 days after coronary ligation, which seems to be related to the presence of a consolidated scar. The authors demonstrated a significant reduction in LF component analyzed by blood pressure (BP) variability, where this component is more representative of the baroreflex sensitivity.

In a heart failure model in dogs, increased sympathetic efferent flux and reduced parasympathetic activity were observed (HRV was evaluated by spectral analysis). During the early asymptomatic phase of cardiac dysfunction, the HF component decreased markedly as decreased the left ventricular peak $+\mathrm{dP} / \mathrm{dt}$. The LF component and the LF/HF ratio showed a gradual increase as symptoms of heart dysfunction progressed. According to the authors, the LVSP and $+\mathrm{dP} / \mathrm{dt}$ decay could probably result in attenuated stimuli to the carotid sinus baroreceptor. These diminished inputs to baroreceptors could potentially inhibit tonic vagal efferent activity to the heart, thereby decreasing HR variability ${ }^{17}$. Other authors have shown a reduced parasympathetic activity at the same time of ventricular dysfunction, with no clinical evidence of heart failure in a similar animal model ${ }^{30}$. These studies corroborate our results since only the animals in the 130 group demonstrated a significant attenuation in the HF component in addition to the presence of congestive signs and cardiac decompensation.

Some questions remain to be explored, such as the most appropriate method for HRV analysis and, primarily, the time frame and the pathophysiological mechanism involved.

In summary, this study demonstrates that the infarcted animals presented left ventricular dysfunction which was influenced by the infarct size. In addition, impairment of autonomic control was demonstrated only in the animals belonging to the 130 group, probably due to the degree of cardiac decompensation and disease progression.

\section{Funding}

Conselho Nacional de Desenvolvimento Científico e Tecnológico (CNPq).

\section{Conflicts of Interest}

The authors declare no conflicts of interest. 


\section{REFERENCES}

1. Yancy CW, Jessup M, Bozkurt B, Butler J, Casey DE JR, Drazner $\mathrm{MH}$, et al. 2013 ACCF/AHA guideline for the management of heart failure: a report of the American College of Cardiology Foundation/American Heart Association Task Force on Practice Guidelines. J Am Coll Cardiol. 2013;62(16):e147-239. http://dx.doi. org/10.1016/j.jacc.2013.05.019. PMid:23747642.

2. Hunt SA, Abraham WT, Chin MH, Feldman AM, Francis GS, Ganiats TG, et al. 2009 focused update incorporated into the ACC/AHA 2005 Guidelines for the Diagnosis and Management of Heart Failure in Adults: a report of the American College of Cardiology Foundation/ American Heart Association Task Force on Practice Guidelines: developed in collaboration with the International Society for Heart and Lung Transplantation. Circulation. 2009;119(14):e391479. http://dx.doi.org/10.1161/ CIRCULATIONAHA.109.192065.

3. Floras JS. Sympathetic activation in human heart failure: diverse mechanisms, therapeutic opportunities. Acta Physiol Scand. 2003;177(3):391-8. http:// dx.doi.org/10.1046/j.1365201X.2003.01087.x. PMid:12609011.

4. Tanai E, Frantz S. Pathophysiology of heart failure. Compr Physiol. 2015;6(1):187-214. http://dx.doi. org/10.1002/cphy.c140055. PMid:26756631.

5. Lazzarini V, Mentz RJ, Fiuzat M, Metra M, O'Connor CM. Heart failure in elderly patients: distinctive features and unresolved issues. Eur $J$ Heart Fail. 2013;15(7):717-23. http:// dx.doi.org/10.1093/eurjhf/hft028. PMid:23429975.

6. Pfeffer MA, Pfeffer JM, Fishbein $\mathrm{MC}$, Fletcher PJ, Spadaro J, Kloner $\mathrm{RA}$, et al. Myocardial infarct size and ventricular function in rats. Circ Res. 1979;44(4):503-12. http:// dx.doi.org/10.1161/01.RES.44.4.503. PMid:428047.

7. Clausell N, Ribeiro JP. In search of new paradigms for the management of heart failure. Arq Bras Cardiol. 1998;71(4):56374. http://dx.doi.org/10.1590/ S0066-782X1998001000002. PMid:10347931.
8. Clausell N, Daly PA, Molossi S, Lima VC, Adelman G, Gotlieb Al, et al. Histological and immunohistochemical characteristics of eccentric coronary artery lesions retrieved by atherectomy from cardiac transplant recipients. Cardiovasc Pathol. 1997;6(1):23-9. http://dx.doi. org/10.1016/S1054-8807(96)00069-5. PMid:25943569.

9. Doggrell SA, Brown L. Rat models of hypertension, cardiac hypertrophy and failure. Cardiovasc Res. 1998;39(1):89-105. http://dx.doi. org/10.1016/S0008-6363(98)00076-5. PMid:9764192.

10. Singh JP, Kandala J, Camm AJ. Nonpharmacological modulation of the autonomic tone to treat heart failure. Eur Heart J. 2014;35(2):77-85. http:// dx.doi.org/10.1093/eurheartj/eht436. PMid:24174128.

11. Hasenfuss G. Animal models of human cardiovascular disease, heart failure and hypertrophy. Cardiovasc Res. 1998;39(1):60-76. http://dx.doi. org/10.1016/S0008-6363(98)00110-2. PMid:9764190.

12. Azevedo ER, Parker JD. Parasympathetic control of cardiac sympathetic activity: normal ventricular function versus congestive heart failure. Circulation. 1999;100(3):2749. http://dx.doi.org/10.1161/01. CIR.100.3.274. PMid:10411852.

13. European Society of Cardiology and the North American Society of Pacing and Electrophysiology. Heart rate variability: standards of measurement, physiological interpretation and clinical use. Circulation. 1996;93(5):104365. http://dx.doi.org/10.1161/01. CIR.93.5.1043. PMid:8598068.

14. Vanderlei LC, Pastre CM, Hoshi RA, Carvalho TD, Godoy MF. Basic notions of heart rate variability and its clinical applicability. Rev Bras Cir Cardiovasc. 2009;24(2):20517. http://dx.doi.org/10.1590/ S0102-76382009000200018. PMid:19768301.

15. National Research Council (NAP). Guide for the care and use of laboratory animals. Washington: NAP; 2018 [cited 2018 Jan 10]. Available from: http://www.nap.edu/ catalog/5140.html
16. Mostarda C, Rodrigues B, Vane M, Moreira ED, Rosa KT, Moraes-Silva IC, et al. Autonomic impairment after myocardial infarction: Role in cardiac remodeling and mortality. Clin Exp Pharmacol Physiol. 2010;37(4):44752. http://dx.doi.org/10.1111/j.14401681.2009.05327.x. PMid:19878213.

17. Ishise $H$, Asanoi $H$, Ishizaka $S$, Joho $\mathrm{S}$, Kameyama T, Umeno K, et al. Time course of sympathovagal imbalance and left ventricular dysfunction in conscious dogs with heart failure. J Appl Physiol. 1998;84(4):123441. http://dx.doi.org/10.1152/ jappl.1998.84.4.1234. PMid:9516189.

18. Kompa AR, Summers RJ. Lidocaine and surgical modification reduces mortality in a rat model of cardiac failure induced by coronary artery ligation. J Pharmacol Toxicol Methods. 2000;43(3):199-203. http://dx.doi. org/10.1016/S1056-8719(00)00103-9. PMid:11257484.

19. Mill JG, Vassallo DV, Leite CM. Time course of changes in heart rate and sympathetic tone after coronary artery ligation in rats. Braz J Med Biol Res. 1991;24(8):855-8. PMid:1797278.

20. De Angelis K, Leirner AA, Irigoyen MC, Cestari IA. Nonstimulated cardiomyoplasty improves hemodynamics in myocardial-infarcted rats. Artif Organs. 2001;25(11):93943. http://dx.doi.org/10.1046/j.15251594.2001.06907.x. PMid:11903150.

21. Norman TD, Coers CR. Cardiac hypertrophy after coronary artery ligation. Arch Pathol. 1960;69:181-4. PMid:14427631.

22. Mill JG, Leite CM, Vassallo DV. Effects of sympathetic block on post-infarction cardiac hypertrophy and their impact on myocardial contractility. Arq Bras Cardiol. 1991;57(6):435-43. PMid:1840467.

23. Schwartz PJ, De Ferrari GM. Sympathetic-parasympathetic interaction in health and disease: abnormalities and relevance in heart failure. Heart Fail Rev. 2011;16(2):101-7. http://dx.doi. org/10.1007/s10741-010-9179-1. PMid:20577900.

24. Mill JG, Stefanon I, dos Santos $\mathrm{L}$, Baldo MP. Remodeling in the ischemic heart: the stepwise progression for heart failure. Braz J Med Biol Res. 2011;44(9):890-8. 
http://dx.doi.org/10.1590/ S0100-879X2011007500096. PMid:21829898.

25. Mortara A, La Rovere MT, Signorini MG, Pantaleo P, Pinna G, Martinelli $\mathrm{L}$, et al. Can power spectral analysis of heart rate variability identify a high risk subgroup of congestive heart failure patients with excessive sympathetic activation? A pilot study before and after heart transplantation. Br Heart J. 1994;71(5):422-30. http:// dx.doi.org/10.1136/hrt.71.5.422. PMid:8011405.

26. La Rovere MT, Specchia G, Mortara A, Schwartz PJ. Baroreflex sensitivity, clinical correlates, and cardiovascular mortality among patients with a first myocardial infarction: a prospective study. Circulation. 1988;78(4):81624. http://dx.doi.org/10.1161/01. CIR.78.4.816. PMid:3168190.

27. Koike MK, Moreira ED, da Silva GJ, Consolim-Colombo FM, Ida $\mathrm{F}$, Irigoyen MC, et al. Resetting of aortic baroreceptors in response to hypotension does not alter gain sensitivity. Clin Exp Pharmacol Physiol. 2006;33(8):679-84. http://dx.doi.org/10.1111/j.14401681.2006.04431.x. PMid:16895539.

28. Rondon E, Brasileiro-Santos MS, Moreira ED, Rondon MU, Mattos $\mathrm{KC}$, Coelho MA, et al. Exercise training improves aortic depressor nerve sensitivity in rats with ischemia-induced heart failure. Am J Physiol Heart Circ Physiol.
2006;291(6):H2801-6. http://dx.doi. org/10.1152/ajpheart.01352.2005. PMid:16798817.

29. Aires R, Pimentel EB, Forechi L, Dantas EM, Mill J. Time course of changes in heart rate and blood pressure variability in rats with myocardial infarction. Braz J Med Biol Res. 2017;50(1):e5511. http://dx.doi. org/10.1590/1414-431x20165511. PMid:28076450.

30. Kinugawa T, Dibner-Dunlap ME. Altered vagal and sympathetic control of heart rate in left ventricular dysfunction and heart failure. $\mathrm{Am}$ J Physiol. 1995;268(2):R310-6. PMid:7864224.

Received: Jan 10, 2018 Accepted: June 12, 2018 